This item was submitted to Loughborough's Research Repository by the author.

Items in Figshare are protected by copyright, with all rights reserved, unless otherwise indicated.

\title{
Open-ended course evaluations: a response rate problem?
}

PLEASE CITE THE PUBLISHED VERSION

PUBLISHER

(C) Emerald

LICENCE

CC BY-NC-ND 4.0

REPOSITORY RECORD

Darby, Jenny A.. 2019. “Open-ended Course Evaluations: A Response Rate Problem?”. figshare. https://hdl.handle.net/2134/2971. 
This item was submitted to Loughborough's Institutional Repository by the author and is made available under the following Creative Commons Licence conditions.

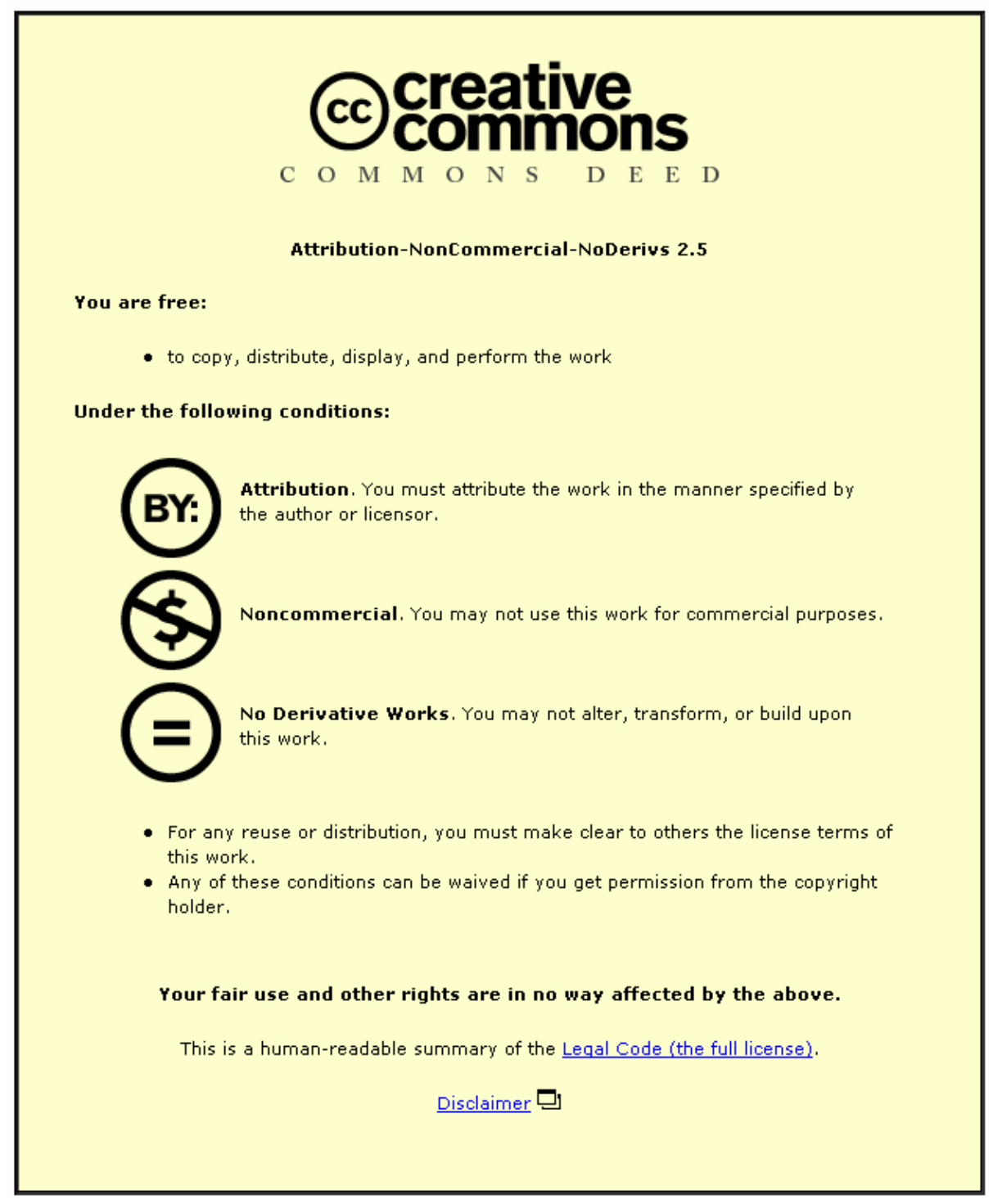

For the full text of this licence, please go to: http://creativecommons.org/licenses/by-nc-nd/2.5/ 


\title{
OPEN ENDED COURSE EVALUATIONS: A RESPONSE RATE PROBLEM?
}

Jenny A. Darby PhD.

Department of Social Sciences, Loughborough University, Loughborough, Leicestershire. LE11 3TU

Research Paper

Key words: evaluation, structured scales, response rates, open-ended.

\begin{abstract}
Purpose - This study examines participant's response rate on dual style training course evaluation forms. These combine structured and open ended formats. Pencil and paper forms have a long history of use by trainers in business and commerce and more recently in education. Research methods texts tend to have neglected the issue of response rates with this type of form.

Design/methodology/approach - Approximately 2000 course participants attending 28 courses completed evaluation forms. These were designed with a series of structured responses scales followed by a section for open ended comments.

Findings - It was found the completion rate for the open ended sections was low and thus validity was suspect. Various explanations were offered for this. Subsequently when a redesigned evaluation form was administered to a further 1641 course participants it was found response rates increased dramatically when open ended sections were placed earlier in the questionnaire.

Practical implications - Indicates ways in which course evaluation forms can be redesigned to increase response rates for open ended sections and thus improve the validity of any findings.

Originality/value - Provides information about response rates neglected by most methodology texts concerning the design of training evaluation questionnaires which include open ended sections.
\end{abstract}

\section{Introduction and overview:}

The aim of the present study is threefold. First, to measure the response rate when open ended sections are placed at the end of course evaluation forms. Second, to identify the reasons for responding or failing to respond on open ended forms. Third, to see whether the response rate can be improved by redesigning the evaluation forms.

Course evaluations, according to Sheldrake and Vickerstaff (1987), have their origins in the business community where value for money for training has long been considered important. It is necessary to evaluate courses, according to Warr, Bird and Rackham 1971, for a number of reasons including the need to monitor the effectiveness of training. Models of evaluating commercial courses have developed from the early work of Kirkpatrick 1983 to more recent studies typified by Smith and Beno 1993. These and many other writers have focussed attention on the importance of the timing of evaluations and the type of measures which should be used to collect data. These measures typically include pencil and paper evaluation forms completed by course participants at the end of their training. This technique tends to be used as it offers, according to Coleman and Lim (2001), a cost effective approach to evaluation. With a desire to evaluate teaching, colleges, universities and OFSTED (Office of Standards in Education) have adopted similar procedures.

Evaluation forms are also used for customer feedback to identify training needs. Needs identification is almost universally accepted by many training management texts, for example Boydell and Leary (1996), Hackett (1997), Hardingham (1996 and 1998) and Siddons (1997), as a preliminary stage in designing any course and therefore as a criteria for later evaluation. A large number of organisations use the same type of pencil and paper questionnaire for this purpose. The present author, for example, obtained information about the techniques used from 35 major hotel chains based in areas including Australia, China, Europe and North America. It was found $91 \%$ used pencil and paper methods of evaluating customer satisfaction, which is surprising bearing in mind the widespread use of Internet booking facilities. Of these $60 \%$ of the evaluation forms used were designed with a series of questions/statements to be answered by means of structured response scales. These are followed by a section for open ended evaluation comments. These forms are also used by many other commercial organisations as a means of identifying training needs and evaluating staff performance. An additional 22 businesses including retail, transport and leisure enterprises similarly geographically spread were surveyed by the author. It was found $50 \%$ used the same dual format with an open ended section at the end of the questionnaire.

Training and research methods texts, of which that by Sommer and Sommer (1997, p. 132) is typical, mention the advantage of combining structured and open ended response formats in the same questionnaire. Schwarz (1999) explains that combining structured response scales and an open ended format allows the questionnaire to elicit a wider variety of information than a fixed response format alone. Strauss and Corbin (1990) argue open ended evaluations provide an opportunity for people to respond freely and express things about the course which concern them. Erickson and Kaplan (2000) mention the virtues of open ended survey questions which they say 'often elicit more honest responses'. Jackson and Trochim (2002) suggest an open ended questionnaire can 'provide a rich description of respondent's reality'. These writers and many training texts, for example Holcomb (1998), Rae (2002), and Salas et al (2003), however, fail to explain fully what the impact is of using a dual style format containing a structured together with an open ended evaluation questionnaire. Rae (1992 p. 111) is one of the few researchers to draw attention to the effects of a dual format. Based on his experience of end of evaluation open ended sections, he reports "comments 
included in this type of space are either rarely made or have little value”. The present author's experience is similar to that of Rae, noting open ended sections of course evaluations which are typically placed at the end of questionnaires are rarely completed. This is important because, if only a small percentage of a sample complete a questionnaire the validity of the results can be questioned. In part one of this study evidence is sought to determine response rates when structured scales are followed by open ended sections on a single evaluation questionnaire.

\section{Part One}

\section{METHOD}

1,989 course evaluation forms from participants attending 28 different modules were analysed. The forms consisted of structured statements which had a five point scale from favourable to unfavourable These contained items listed in table I. In addition to the structured evaluation questions, at the end of the questionnaire there was an opportunity, following Rae (1992 p 110), for course participants to make statements in an open ended format. There were three stimulus statements for this section as can be seen in table I.

Table I

Example of the structured response evaluation statements used with the undergraduates

\begin{tabular}{|l|}
\hline \multicolumn{1}{|c|}{ Statements } \\
\hline Liking of module content statements \\
The module has helped me think critically \\
The module has given me a good understanding of the subject \\
The way the module is delivered has encouraged me to participate \\
\hline Resources statements \\
The library has the books and resources I need for this module \\
The teaching rooms for this module were fit for their purpose \\
Projectors, boards and screens were adequate for this module \\
The computing facilities I needed for this module were satisfactory \\
\hline Liking presenter statements \\
The lecturer was well prepared \\
The lecturer communicated clearly and effectively \\
The lecturer was enthusiastic about the subject \\
The lecturer was a good teacher \\
\hline Would you like to expand on any of the above? \\
\hline What did you like about this module? \\
\hline How could this module best be improved?
\end{tabular}

\section{Participants}

Evaluation forms from an undergraduate sample were used in this study as large numbers of course participants were required for the data to be meaningful. It was also essential, due to the nature of the open ended responses, that the sample be considered to have the literary ability to complete the written forms. Failure to ensure this could have resulted in the criticism, that rather than the design of the questionnaire being tested, the reason for a poor response rate was that those completing the forms were not 'able' to write their comments. The modules evaluated included a range of education and social science subjects. The same format was used for all the evaluation forms. The numbers attending modules ranged from 10 to 162 with a mean of 76.71 . This included a range of class sizes for Defusco (1999) has shown smaller classes tend to evaluate more favourably than larger

\section{Analysis of the forms}

The twelve structured statements, outlined in table I were analysed individually on five point scales from agree to disagree indicating very poor to very good. This was scored in terms of a minimum score of 1 and maximum of 5 . They were classified into three categories by five raters acting independently. The first included items concerning the presenters/tutors, other members of the group and participation in class (after Parrot et al 1988). The second, concerned 'feelings about content' which referred to the material presented which, according to Furedi, F. (2003), is an important measure of student evaluation. The third, included items to do with teaching resources (after Herzberg 1966).

The statements on the open-ended evaluation forms were placed in the same three categories as the structured responses by the researcher. Twenty per cent were selected at random by an assistant, who was instructed in the categorisation scheme. Totally independently a total of 70 forms were scored by this assistant. 205 individual statements on these forms were placed in categories and 181 were placed by the assistant in the same categories as the researcher. This was a $88.5 \%$ matching rate. 


\section{Numeric scoring of the open ended evaluations:}

The reason for categorising the scales and allocating numerical scores to the responses was to permit statistical comparisons to be made between the scaled and open ended responses. The evaluations of the participants on the open ended section were scored according to the order of the comments made. The 'positive/favourable' comments were recorded separately from the 'negative/unfavourable' comments. For each the first comment made was awarded a score of four the second comment was awarded three, the third comment was awarded two, and the fourth and subsequent comments were awarded one. When there was no comment that category was awarded zero. This took into account the order effect noted by Sherman and Klein, (1994); Wyer et al, (1994) and Swann and Gill, (1997). The order effect draws attention to the fact that people tend to react first to the thing which to them is most important, then the next item they refer to is less important and so on.

\section{RESULTS}

Of the 1,989 evaluation forms the open ended section was only completed on 472 . That is a response rate of $23.74 \%$. It would appear when participants complete a structured evaluation less than one in four go further and make comments in the open ended section. It should be noted there was a $94 \%$ response rate for completing all of the structured scales on any individual response form.

The data was checked to see whether the open ended responses were linked consistently with either positive or negative comments about the modules using the numerical analysis described above. Using a t-test for related samples it was found there was no significant difference between the number of comments which were positive or negative concerning the course (positive mean 8.38, negative mean 8.09, $\mathrm{t}=.262$. df 27). Similarly there was no significant difference in the number of comments listed under the section asking students to expand on their previous structured responses and whether they were positive or negative responses (expand/positive $t=.990$ p .334 ; expand/negative $t=1.81$ p .084 ).

Finally the overall score on the structured evaluation section for all the statements concerning the liking of the module content, resources and the presenter were correlated (presenter ,241 p >. 294, content -.007 p>.976; resources .199 $\mathrm{p}>.388$ ) and for negative comments (presenter $.143 \mathrm{p}>.536$, content $-.045 \mathrm{p}>.846$; resources $.308 \mathrm{p}>.175$ ). There would appear to be no evidence of any link between positive or negative reactions expressed on the structured scale and the open ended sections of the evaluation returns. This would suggest the students were expressing different views about the course they attended by means of the two methods of evaluation.

\section{Part two}

In an attempt to understand more about why course participants complete evaluation forms in the manner they do a questionnaire was given to undergraduates attending two courses. They were asked questions about their manner of responding on evaluation forms they had recently completed. These students had not been included in part one of the present study. Again undergraduates were used as few 'follow on' courses with large numbers of participants are available in business and commercial training programmes.

\section{METHOD}

Participants:

These were 202 first year undergraduates who attended a lecture (267 were registered on the course), and 155 second and third year undergraduates who attended another lecture (185 were registered). All those present on each occasion returned the questionnaires. Both courses were social science courses. It was administered during lectures in the second week, of the second semester of the academic year. All course participants had completed evaluation forms at the end of each of the three modules they had taken during the first semester. The questions on the current questionnaire referred to how they had filled in those evaluation forms.

The questionnaire:

The course participants were asked whether they had completed the open ended sections and what type of comment they made, why they did so, and if they did not do so, why not. The evaluation questionnaire referred to was that described in table I.

\section{RESULTS}

$64.5 \%$ of the sample stated they completed the open ended section of at least one of the, in most cases, three evaluations they completed in the previous semester. Obviously this figure is higher than that actually observed in part one when responses to one individual modules were examined. Here they are asked whether they filled in the open ended sections on any one or more of the three module evaluations they had just completed. It was also possible the present group of students may, according to Schwarz et al (1991) have said they responded to create a favourable impression which could also have contributed to this higher response rate. They were asked about the comments they had made. As can be seen in table II most people report they made a mixture of comments, less reported they made unfavourable and the least number made favourable comments. 
Table II

Showing responses to questions:

Were the comments you made (please tick as appropriate) Mainly favourable: mainly unfavourable: a mixture

\begin{tabular}{|l|c|}
\hline \multicolumn{1}{|c|}{$\begin{array}{c}\text { Type of comment } \\
\text { n=230/357 }\end{array}$} & $\begin{array}{l}\text { Percentage of students saying th } \\
\text { made the particular type of } \\
\text { comment }\end{array}$ \\
\hline Mainly favourable about the module & $(14 \%)$ \\
\hline Mainly unfavourable about the module & $(33 \%)$ \\
\hline A mixture & $(53 \%)$ \\
\hline
\end{tabular}

Course members were asked why they had completed the open ended section. The percentages in table III show the main reason given for completing the open ended section, was to expand on what they have said in the tick boxes. A second reason was to try to make things better for the future.

Table III

Answers to question: 'Briefly explain why you completed the open ended section at the end of the form?'

\begin{tabular}{|l|c|}
\hline Type of comment n=230/357 & $\begin{array}{l}\text { Percentage of students saying th } \\
\text { main reason they completed the } \\
\text { open ended section was }\end{array}$ \\
\hline $\begin{array}{l}\text { To explain more fully my responses in the ti } \\
\text { boxes }\end{array}$ & $13.7 \%$ \\
\hline $\begin{array}{l}\text { To try to make things better for } \\
\text { the future }\end{array}$ & $10.4 \%$ \\
\hline $\begin{array}{l}\text { To express my opinion on matters not covere } \\
\text { by the tick boxes }\end{array}$ & $8.4 \%$ \\
\hline $\begin{array}{l}\text { To express my views about a bad lecturer, o } \\
\text { other aspects of the course }\end{array}$ & $3.1 \%$ \\
\hline $\begin{array}{l}\text { To express my views about a } \\
\text { good lecturer or other aspects of the course }\end{array}$ & $2.2 \%$ \\
\hline Were instructed to do so on the form & $1.1 \%$ \\
\hline
\end{tabular}

Course members were asked to give their most important reason for not completing the open ended sections. As can be seen in table IV, the highest percentage felt they had said it all in the forced choice tick boxes. The next most commonly mentioned reason was that they could not be bothered.

Table IV

Answers to question: 'Can you tell me why you did not complete the open ended section on the evaluation form?'

\begin{tabular}{|l|c|}
\hline Type of comment n=127/357 & $\begin{array}{l}\text { Percentage of students saying th } \\
\text { main reason they did not compl } \\
\text { the open ended section was } \\
\text { because }\end{array}$ \\
\hline $\begin{array}{l}\text { I felt I had said all there was to } \\
\text { say in the forced choice Questions }\end{array}$ & $12.0 \%$ \\
\hline $\begin{array}{l}\text { I could not be bothered to } \\
\text { complete it }\end{array}$ & $10.3 \%$ \\
\hline $\begin{array}{l}\text { I felt uncomfortable making } \\
\text { written comments }\end{array}$ & $3.3 \%$ \\
\hline \begin{tabular}{l} 
I had no time to complete it \\
\hline $\begin{array}{l}\text { I did not know enough about the content of th } \\
\text { course to } \\
\text { make judgements about it }\end{array}$
\end{tabular} \\
\hline
\end{tabular}




\section{Part three}

The aim of the third part of this study was to see whether the low response rate for completion of the open ended section could be improved by redesigning the evaluation forms. It is rare for open ended questions to be made the primary focus of evaluations and so the observations of Alloy, Acocella and Bootzin (1996. p103) are helpful in that they explain much of our behaviour is influenced by the `demand characteristics of the situation`. This refers to things which influence our expectations of how we should behave. Bernstein and Nash (1999 p195), for example, suggest when something is at the end of a series, it is seen as being of less importance than something earlier in the series and so less notice is taken of it. The expectation for us to react is less likely as it is seen as being less important. This view can be related to dual style evaluation forms. The observations of course participants themselves, reported in part two of this study, indicate they have little to add to what they have already ticked on the structured response form. Following from this, it could be implied, that by putting the open ended statements at the beginning of a dual style evaluation format, the `demand characteristics` are likely to encourage the student to complete it. Orne (1962) emphasised the fact that anything in a situation, which encourages an individual to do something, can increase the likelihood of that act being carried out. Essentially what is being done when the open ended section is placed at the beginning of the questionnaire is to raise its profile. This is to be done in this part of the study. According to Orne, the 'demand' or the expectation on the subject to complete it is also far greater. A third method of using open ended evaluations included in this study is described by Rae (1997 p. 1). This involves a mixed format where each sub group of questions, (shown in table I), is followed by its own open ended question.

\section{METHOD}

1,641 undergraduates attending twelve education and social science modules completed evaluation forms at the end of each of their lecture series. The modules were selected on the basis of contacts in the Education and Social Sciences departments where the researcher was tutoring undergraduates. The evaluation form used was that described in part one, but modified by the researcher. Distributed randomly one third of the students in each module were given the evaluation form with the open ended section at the end of a structured evaluation form. One third were given the evaluation with the open ended section at the beginning of the form, and for the final third (in the mixed condition) the open ended section was located after each subgroup of structured statements. The instructions given the students for completion of the form followed the same script for all students regardless of the style of evaluation form they completed.

\section{RESULTS}

As can be seen in table V more open ended statements were completed (81.9\%) by students given the open ended responses at the beginning of the form, or in the mixed condition (63\%) than those given it at the end (31.6\%). It should be noted that the response rate for completing all of the structured scales on any individual form was $93.4 \%$ regardless of where they were placed on the forms.

Table V

Showing the number of people who completed the open ended sections of the evaluation questionnaires out of the 1641 collected from 12 modules

\begin{tabular}{|l|c|c|c|}
\hline Layout of questionnaire & $\begin{array}{l}\text { Number of } \\
\text { questionnaires } \\
\text { collected }\end{array}$ & $\begin{array}{l}\text { Number of open } \\
\text { ended sections } \\
\text { completed }\end{array}$ & $\begin{array}{l}\text { Percentage of open } \\
\text { ended sections } \\
\text { completed }\end{array}$ \\
\hline Open ended at end of questionnaire & 549 & 174 & $31.6 \%$ \\
\hline $\begin{array}{l}\text { Open ended after each } \\
\text { section of (mixed) questionnaire }\end{array}$ & 554 & 350 & $63.0 \%$ \\
\hline $\begin{array}{l}\text { Open ended at beginning } \\
\text { of questionnaire }\end{array}$ & 538 & 441 & $81.9 \%$ \\
\hline
\end{tabular}

\section{DISCUSSION}

Rae's (1992) insight into the low response rate for open ended sections located at the end of a structured evaluation form is supported by the present study. In part three only $31.6 \%$ of respondents completed the open ended sections placed at the end. This is slightly higher than that found in part one but still a low response rate for a questionnaire study. Hayes (2000 p87), notes that a typical postal questionnaire could have a response rate as low as 20 or 30 per cent. and if so validity should be questioned. This raises the question of whether it matters if less than a third of the respondents make use of the open ended section of an evaluation form. The answer to this very serious methodological question must take into account issues of sampling. If only a small proportion of a sample respond, then according to Hayes (2000 p249), the information given by the respondents should not be considered representative. Certainly the research literature on voluntary participation, of which Rosenthall (1965) is typical, would indicate that any study employing only $25 \%$ of the population on a voluntary basis could not claim to be a random sample. More recently Paolo et al (2000) note low response rates with evaluations 'limit the generalizability of some of the findings'. Perhaps this is what Rae (1992 p. 111) means when he says the comments have "little value". The low response rate noted in the present study does raise the question of whether it is appropriate to add an open ended evaluation section to the end of a structured questionnaire. This makes it possible the sample is not truly representative and so raises questions about a consequent lack of meaning, or validity. Training texts generally do not draw attention to this problem. In this study undergraduates were used because of the need to look at large numbers. These findings can, however, realistically be 
related to HRD as there is every reason to believe the undergraduates responded on the evaluation forms in a similar manner to how they will respond a year or two in the future when many of them will become management trainees.

Some reasons for the poor response rate of open ended evaluations located at the end of questionnaires are outlined in part two of this study. The main reason given is that respondents did not complete the open ended sections at the end of questionnaires because they 'felt they had already expressed their feelings on the previous rating scales'.

Part three of this study has provided a useful insight into the way response rates can be raised. This can be achieved by moving the open ended section to the beginning of the questionnaire, or having an open ended section after each subgroup of structured style statements. It should be stressed this was achieved without the use of any verbal prods, or variation in written instructions. The instructions were the same for each of the three questionnaire formats. This appears to have no effect on the response rate of the structured scales. Whether these are located at the beginning or the end of the questionnaire the response rate is over ninety percent.

Making open ended sections more prominent does appear to increase response rate and thus validity. The issue of validity is extremely important when the widespread use of pencil and paper evaluations is taken into account. It is not being suggested here that business, commercial and educational organisations should discard dual style questionnaires. There is, however, a need to consider very carefully, when response rates are low, how findings from open ended sections are interpreted. It is well worth endeavouring to improve response rates for there are advantages to be had from dual style questionnaires. The structured section ensures all areas of interest to those running a course are covered and the open ended section allows the respondents to express their views freely.

Further research needs to be carried out to determine whether low response rates observed here apply to other uses of these forms. For example, customer satisfaction surveys which have open ended sections at the end were shown earlier to be in common use often for purpose of identifying training needs. A second area for investigation concerns the type of comments made in the open ended sections. In part two of the present study the respondents claimed they made a mixture of positive and negative comments. The balance between positive and negative comments given when the open ended section is at the end of the questionnaire may well not be the same as when it is placed earlier in the format. This needs further investigation as it could influence any evaluation.

From the practical point of view, when using dual style response forms to evaluate training courses it is essential that response rates for open ended sections are calculated to ensure the sample is representative. There are no hard and fast rules for an acceptable response rate but many researchers have provided guidelines as to what would be considered reasonable. For example Lawler (1993) found with a postal questionnaire a return rate of $49 \%$ acceptable. Paolo et al (2000) in a survey of postal student evaluation questionnaires reported an average $41 \%$ response rate. Response rates below these levels should be cause for concern for those carrying out the survey. The present study has demonstrated how they can be improved by redesigning the form. The format most suitable will depend on the content of the form and it may well be necessary to vary the approach to suit individual requirements. The response rates achieved in the present study may well provide a useful benchmark.

\section{Acknowledgement:}

This empirical study is integrated in the author's own doctoral thesis.

\section{REFERENCES}

Alloy, L.B: Acocella, J. and Bootzin, R. (1996) Abnormal psychology: current perspectives. New York. McGraw-Hill

Bernstein, D.A. and Nash, P.W. (1999) Essentials of Psychology. Boston. New York. Houghton Mifflin and Co.

Boydell, T. \& Leary, M. (1996) Identifying Training Needs. Wiltshire. The Cromwell Press.

Coleman, P.T. and Lim, Y.Y.J. (2001) "A systematic approach to evaluating the effects of collaborative negotiation training on individuals and groups”. Negotiation Journal. Oct, 363-392.

Defusco, M.B. (1999) “An exploration of the relationship between class size and students' ratings of teaching quality at the University of Phoenix: Do adult students make a difference?” Dissertation Abstracts International_section A: Humanities and Social Sciences. 60. 6-A. 1901.

Erickson, P. I. and Kaplan, C.p. (2000) "Maximizing qualitative responses about smoking in structured interviews". Qualitative Health Research. 10. 829-840

Furedi, F. (2003) “Students are not customers”. Autlook 226. 13.

Hayes, N. (2000) Doing psychological research. Buckingham. Philadelphia. Open University Press

Hackett, P. (1997) Introduction to training. London Institute of Personnel and Development.

Hardingham, A. (1996). Designing Training. Wiltshire. The Cromwell Press. 
Hardingham, A. (1998). Psychology for Trainers. Wiltshire. The Cromwell Press.

Herzberg, F. (1966). Work and the Nature of Man. Cleveland. World Publishing.

Holcomb, J. (1998) Training evaluation made easy: Making your training worth every penny. Kogan Page.

Jackson, K.M. and Trochim, W.M.K. (2002) “Concept mapping as an alternative approach for the analysis of openended survey responses”. Organisational Research Methods. 5. 4. 307-336

Kirkpatrick, D.L. (1983) Supervisory Training and Development. $2^{\text {nd }}$ ed. Addison-Wesley Publishing Co. Reading M.A.

Lawler, M. (1993) “Assessment of the likelihood of primary school teachers believing children’s disclosure of sexual abuse”. Child Abuse Review. 2. 3. 174-184.

Orne, M.T. (1962) "On the social psychology of the psychological experiment: with particular reference to demand characteristics and their implications”. American Psychologist. 17. 776-783.

Paolo, A.M. Bonaminio, G.A., Gibson, C. Partridge, T. and Kallail, K. (2000)

"Response rate comparisons of e-mail and mail-distributed student evaluations". Teaching and Learning in Medicine. 12. 2. 81-84

Parrot, W.G., Sabini, J.and Silver, M. (1988) “The roles of self-esteem and social interaction in embarrassment”. Personality and Social Psychology Bulletin._14. 191-202

Rae, L. (1992) Assessing trainer effectiveness. Gower. Hants. England.

Rae, L. (1997) ( $3^{\text {rd }}$ edition). How to Measure Training Effectiveness. Hampshire, England. Gower Publishing Ltd.

Rae, L. (2002) Assessing the value of your training: The evaluation process from training needs to the report to the board. Aldershot, UK: Gower Publishing Co.

Rosenthal, R. (1965) “The volunteer subject”. Human Relations. 18. 389-406

Salas, E. Milham, L.M. and Bowers, C.A. (2003) "Training evaluation in the military: Misconceptions, opportunities, and challenges”. Military Psychology 15.1. 3-16

Schwarz, N, Knauper, B Hippler, H.J. Noelle-Neumann, E. and Clark, F .(1991) "Rating scales: numeric values may change the meaning of scale labels”. Public Opinion Quarterly 55. 570-582

Schwarz, N. (1999) “Self-reports: How questions are answered”. American Psychologist. 54. 2. 93-105

Sheldrake, J. and Vickerstaff, S. (1987) The history of industrial training in Britain. Aldershot. Uk. Avebury. Gower.

Sherman,J.W. and Klein, S.B. (1994) “Development and representation of personality impressions”. Journal of Personality and Social Psychology. 67, 972-983

Siddons, S. (1997). Delivering Training. Wiltshire. The Cromwell Press.

Smith, C. and Beno, B. (1993) Guide to staff development evaluation. (ERIC Document Reproduction Service No. ED 363 381)

Strauss, A., \& Corbin, J. (1990). Basics of Qualitative Research. Newbury Park, California. Sage Publications.

Sommer, B. and Sommer, R. (1997) A practical guide to behavioural research. $4^{\text {th }}$ edit. New York: Oxford University Press.

Swann, W.B. Jr. and Gill,M.J. (1997) "Confidence and accuracy in person perception: Do we know what we think we know about our relationship partners?” Journal of Personality and Social Psychology, 73. 747-757

Warr, P., Bird, M. \& Rackham, N. (1971). Evaluation of Management Training, London. Gower Press.

Wyer,R.S. Jr. Budesheim, T.I, Lambert, A.J. and Swan, S. (1994) "Person perception judgement: Pragmatic influences on impressions formed in a social context”. Journal of Personality and Social Psychology. 66. 254-267. 


\section{About the author:}

Jenny Darby has a varied career in Education. She taught in an inner city Comprehensive school for 25 years completing her service as Head of Science. For two years during a secondment she was responsible for a county wide training programme for head teachers and senior teaching staff. She has recently been running training workshops in teaching skills for postgraduates at Loughborough University, where she completed her doctorate. Her main research interest concerns evaluation of training programmes.

E mail J.A.Darby@lboro.ac.uk 